\title{
PENGEMBANGAN APLIKASI PENCARIAN KLINIK DENGAN ALGORITMA
} BELLMAN FORD

\author{
Suyanto $^{1}$, Andri $^{2}$ \\ ${ }^{1}$ Program Studi Sistem Informasi, Universitas Bina Darma, Palembang \\ e-mail:*11 suyanto@binadarma.ac.id, ${ }^{2}$ andri@binadarma.ac.id
}

\begin{abstract}
Abstrak
Layanan kesehatan merupakan hak bagi setiap orang, termasuk di dalamnya yaitu untuk memilih fasilitas kesehatan yang ia inginkan. Salah satu fasilitas kesehatan adalah klinik dimana klinik merupakan fasilitas kesehatan yang lokasinya dekat dengan permukiman penduduk. Kota Palembang merupakan salah satu kota yang memiliki penduduk cukup banyak baik penduduk asli Kota Palembang ataupun penduduk datangan. Bagi sebagian penduduk lokasi fasilitas kesehatan tidak begitu perduli sehingga ketika dibutuhkan banyak dari penduduk tersebut tidak mengetahuinya. Untuk itu di dalam penelitian ini dilakukan pembuatan aplikasi yang dapat digunakan untuk melakukan penarian lokasi sekaligus memberikan alternatif rute perjalanan yang paling pendek. Di dalam penentuan alternatif rute perjalanan tersebut di gunakan algoritma Bellman Ford sebagai proses untuk menigkatkan kebenaran perhitungan. Proses pengembangan aplikasi juga menggunakan metode rational unified process agar pengembangan terarah sesuai kaidah ilmiah. Hasil dari penelitian berupa aplikasi yang di dalamnya dilakukan implementasi algorima Bellman Ford. Dari hasil penelitian menunjukkan bahwa algorima Bellman Ford mampu untuk melakukan perhitungan secara rinci terhadap rekomendasi rute yang diberikan pada aplikasi kondisi tersebut dapat dilihat dari iterasi perhitungan yang dilakukan.
\end{abstract}

Kata kunci-Aplikasi, Klinik, Algorima, Bellman Ford

\begin{abstract}
Health services are a right for everyone, including to choose the health facilities they want. One of the health facilities is a clinic where the clinic is a health facility located close to residential areas. Palembang City is one of the cities that has quite a number of residents both the original inhabitants of Palembang City and migrants. For some residents the location of health facilities does not really matter so that when needed many of these residents do not know. For this reason, in this study, an application was made that could be used to conduct location dances while providing the shortest alternative travel route. In determining the alternative travel routes, the Bellman Ford algorithm is used as a process to increase the accuracy of calculations. The application development process also uses the rational unified process method so that development is directed according to scientific principles. The results of this research are applications in which the Bellman Ford algorithm is implemented. From the results of the study show that the Bellman Ford algorithm is able to perform detailed calculations of the recommended recommendations given in the application of these conditions can be seen from the iteration of the calculations performed.
\end{abstract}

Keywords-Application, Clinic, Algorithm, Bellman Ford 


\section{PENDAHULUAN}

Perkembangan teknologi mobile dalam hal ini smartphone terutama yang berbasis android dan iOS menjadikan masyarakat memiliki kebutuhan yang lebih akan aplikasi berbasis mobile yang dapat menunjang kebutuhan mereka sehari-hari. Penggunaan aplikasi mobile sendiri saat ini telah terbukti memudahkan penggunanya dalam memenuhi kebutuhan seperti berbelaja, pencarian tempat dan kebutuhan lainnya. Penggunaan perangkat mobile di Indonesia telah menigkat dari waktu ke waktu yang dibuktikan dari masuknya Indonesia ke lima besar pengguna perangkat mobile tersebut [1].

Pendapat lain mengatakan bahwa penggunaan perangkat mobile terutama smartphone tenah menigkat lebih tinggi yang dibuktikan dengan pertumbuhan pengguna smartphone yang semakin fantastis [2]. Berdasarkan data pengguna smartphone pada tahun dua ribu eman belas tercatat lebih kurang 65,2 pengguna, pada tahun dua ribu tuhuh belas tercatat lebih kurang 74,9 pengguna dan diperkirakan akan terus mengalami pertumbuhan yang signifikan mulai dari 83,5 juta hingga 92 juta orang pengguna perangkat mobile di Indonesia. Khususnya di provinsi sumatera selatan perkembangan smartphone sudah sangat pesat di buktikan dengan data yang menunjukan pengguna smartphone di palembang mencapai 56\% [3].

Palembang merupakan ibu kota dari Provinsi Sumatra Selatan, sebagai ibu kota Provinsi, tentunya Palembang memiliki daya tarik tersendiri sehingga memiliki penduduk yang banyak serta banyak diminati pengunjung. Palembang juga merupakan dengan pertumbuhan yang tinggi baik dari fisik maupun layanan yang diberikan ke masyarakat. Kondisi tersebut tentunya dapat dilihat di berbagai bidang terutama dalam bidang kesehatan yang dibuktikan dengan banyaknya klik kesehatan yang ada.

Informasi klinik kesehatan terdekat berguna bagi masyarakat terutama bagi masyarakat yang mengalami sakit, kecelakaan dan lain-lain. Klinik kesehatan merupakan salah satu tempat yang menjadi tujuan bagi masyarakat ketika membutuhkan layanan kesehatan. Sehingga informasi berkaitan dengan lokasi dan jarak fasilitas kesehatan seperti klinik menjadi sangat penting dan perlu untuk diketahui oleh masyarakat sebagai alternatif dalam memilih tujuan berobat.

Untuk itu kebutuhan navigasi atau petunjuk bagi masyarakat dalam memilih fasilitas kesehatan terutama klinik menjadi sesutu yang penting untuk dilakukan. Kondisi tersebut juga didukung oleh kondisi Kota Palembang yang cukup luas dimana masyarakat yang tinggal tentunya banyak dari daerah di luar Kota Palembang. Informasi keberadaan klinik atau fasilitas kesehatan sendiri diperlukan bagi masyarakat dalam keadaan darurat atau mendesak seperti kecelakaan atau melahirkan. Sebagai solusi dari kondisi tersebut tentunya dapat diatasi dengan melakukan implementasi algoritma untuk menentukan jarak ke lokasi yang dalam hal ini fasilitas kesehatan seperti klinik. Salah satu algoritma yang mampu untuk melakukan penentuan tersebut yaitu algoritma Bellman Ford. Algorima ini memiliki kemampuan dalam menghitung jarak terpendek dari satu lokasi ke lokasi tertentu sesuai dengan bobot [4]. Sehingga akan sangat membantu masyarakat dalam mencari lokasi dan menentukan rute perjalanan menuju klinik jika keadaan mendesak

Berdasarkan uraian yang telah disampaiakan maka penelitian ini akan melakukan pengembangan aplikasi pencarian klinik dengan menerepkan algoritma Bellman Ford, dimana pertanyaan 
penelitian berupa "bagaimana menerapkan algoritma bellman - ford ke dalam aplikasi pencarian klinik kesehatan?". Sedangkan batasan dalam melakukan penelitian yang terdiri dari: (1) lokasi klinik kesehatan yang digunakan hanya klinik keseahatan yang ada di Kota Palembang. (2) rute jalan yang digunakan di anggap jalan utama, tidak termasuk jalan-jalan kecil/gang. (3) uji coba aplikasi sementara hanya di kota Palembang [5].

\section{TINJAUAN PUSTAKA}

Teori dan kajian terkait dengan penelitian yang peneliti lakukan dapat dijelaskan sebagai berikut:

\subsection{Algoritma}

Algoritma merupakan kumpulan perintah yang saling berkaitan untuk menyelesaikan suatu masalah. perintahperintah ini dapat diterjemahkan secara bertahap dari awal hingga akhir. Dalam penyusunannya diperlukan urutan serta logika agar algoritma yang dihasilkan sesuai dengan yang diharapkan. Algoritma merupakan bagian yang terpenting dan tidak dapat dipisahkan dari program. Meskipun sintaksis dan semantik yang dibuat benar adanya, dengan algoritma yang keliru, permasalahan yang ingin dipecahkan dengan teknik pemrograman tidak akan berhasil. Oleh karena itu, sebelum membuat suatu program aplikasi, hal pertama yang harus kita pahami adalah algoritma atau prosedur pemecahannya. Hal ini bertujuan agar program yang telah dibuat dapat sesuai dengan yang diharapkan [6].

\subsection{Algoritma Bellman - Ford}

Algoritma Bellman-Ford merupakan untuk mencari shortest path. Algoritma ini akan menghitung jarak terpendek (dari satu sumber vertex tertentu) pada sebuah graph. Maksud dari satu sumber adalah bahwa algoritma ini menghitung semua jarak terpendek yang berawal dari satu titik vertex tertentu ke seluruh vertex lain dalam sebuah graph yang berbobot dan terarah [7].

Algoritma ini menggunakan $\mathrm{d}[\mathrm{u}]$ sebagai batas atas dengan jarak $\mathrm{d}[\mathrm{u}, \mathrm{v}]$ dari $\mathrm{u}$ ke v. Algoritma ini melakukan inisialisasi jarak titik sumber ke titik nol dan semua titik lainnya (sampai takhingga). Secara progresif algoritma ini melakukan perbaikan (updating) jarak pada setiap titik sumber ke titik v di dalam $\mathrm{V}$ hingga di capai lintasan dalil Bollean TRUE yaitu jarak negatif mengandung lingkaran tidak negatif maka titik dapat di capai dari titik sumber, dan dalam kondisi lain dikatakan Bollean FALSE, Algoritma Bellman-Ford sebagai berikut [8]:

1. INITIALIZE-SINGLE-SOURCE $(\mathrm{G}, \mathrm{s})$

2. for each vertex $i=1$ to $V(G)-1$ do

3. for each edge $(u, v)$ in $E[G]$ do

4. $\operatorname{RELAX}(\mathrm{u}, \mathrm{v}, \mathrm{w})$

5. For each edge $(u, v)$ in $E[G]$ do

6. if $d[u]+w[u, v]<d[v]$ then

7. return FALSE

8. return TRUE

\subsection{Penelitian Terdahulu}

Peneltian terkait dengan algorimat bellman ford sebenarnya telah ada dilakukan diantaranya adalah dalam penentuan jalur terpendek untuk menuju sebuah café yang ada di Kota Malang. Penelitian tersebut dijelaskan bahwa Bellman Ford digunakan untuk menghitung jalur yang akan ditempuh termasuk jalur alternatif sesuai dengan graf yang telah ditentukan, dimana lokasi awal sesuai dengan titik koordinat GPS. Penelitian tersebut menghasilkan aplikasi yang menampilkan informasi jarak jalan, lokasi persimpangan sesuai dengan koordinat lokasi pengguna dan tujuan pengguna [9].

Penelitian lain juga berkaitan dengan Bellman Ford adalah dalam mencari rute stasiun pengisian bahan bakar umum 
(SPBU). Di dalam penelitian tersebut digunakan aplikasi berbasis android untuk mencari jalur untuk menuju SPBU menggunakan algoritma Bellman Ford. Hasil penelitian tersebut menunjukan bahwa algoritma Bellman Ford mampu untuk memberikan alternative rute dalam menuju SPBU. Untuk menentukan lokasi awal pengguna digunakan koordinat GPS smartphone dan dalam penentuan jalur bagi pengguna akan menampilkan tiga rekomendasi alternatif rute pilihan [5].

\section{METODOLOGI PENELITIAN}

Untuk menyelesaikan proses penelitian dalam hal ini pengembangan aplikasi pencarian klinik kesehatan dengan mengimplementasikan algoritma Bellman Ford maka metode-metode yang digunakan dapat dijelaskan sebagai berikut:

\subsection{Metode Penelitian}

Metode penelitian adalah proses bagaimana penelitian dilakukan. Untuk itu di dalam penelitian ini digunakan metode penelitian deskriptif. Metode deskriptif dijelaskan bahwa metode penelitian yang mengungkapkan fenomena sesuai fakta dan kejadian yang dilihat dari sudut pandang peneliti. Metode deskriptif juga dapat dikatakan sebagai penjabaran objek yang diteliti yang dilihat dari perspektif peneliti itu sendiri [10]. Dengan demikian penggunaan metode penelitian deskriptif sangat tepat mengingat penelitian yang dilakukan berkaitan dengan implementasi algoritma Bellman Ford dalam proses penentuan rute untuk menuju sebuah klinik yang dapat digunakan oleh masyarakat ketika membutuhkan informasi rute perjalananan dalam keadaan darurat atau kondisi lainnya saat diperlukan.

\subsection{Metode Pengembangan}

Metode pengembagnan merupakan metode yang digunakan dalam proses pengembagnan aplikasi dalam implementasi algoritma Bellman Ford untuk menentukan rute perjalanan menuju fasilitas kesehatan yang dalam hal ini klinik kesehatan. Untuk itu metode yang digunakan adalah metode Rational Unified Process (RUP). RUP adalah pendekatan pengembangan aplikasi yang bersifat berulang-ulang atau sering dikenal dengan iterative. Focus dari metode ini adalah arsitektur dan berdasarkan penggunaan kasus (use case-driven). Dalam proses pengembangan dengan RUP memiliki fase seperti pada Gambar 1 [11].

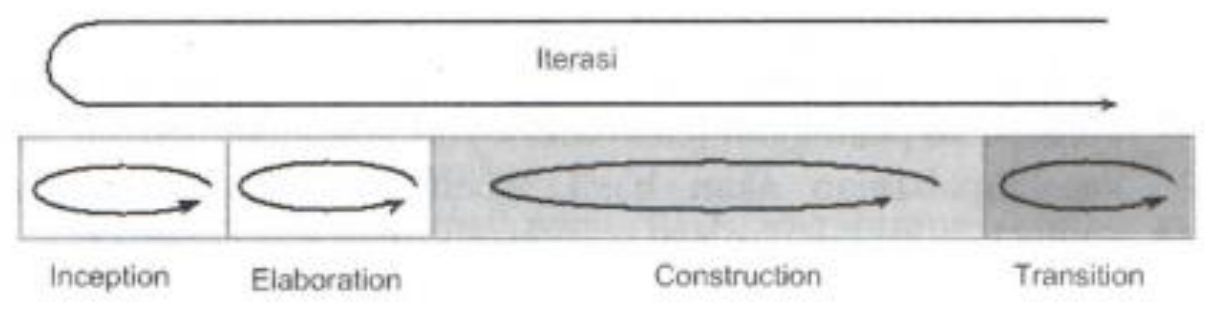

Gambar 1. Fase RUP

- Inception (permulaan), proses pekerjaan yang dilakukan pada fase inception meliputi penentuan kebutuhan atau proses bisnis dari aplikasi yang akan dihasilkan.
Penentuan kebutuhan tersebut dilakukan dengan cara membuat pemodelan aplikasi dalam bentuk diagram use case dari unified modelling language. 
- Elaboration (perluasan/perencanaan), proses pekerjaan yang dilakukan pada fase ini dilakukan desain dari aplikasi yang akan dihasilkan. Desain yang dibuat meliputi desain arsitektur aplikasi. Desain arsitektur meliputi desain basis data utama, desain pembentuk aplikasi seperti class diagram. Semua desain tersebut tentunya akan diimplementasikan pada fase construction atau pengkodean.

- Construction (konstruksi), proses pekerjaan yang dilakukan pada fase ini adalah melakukan implementasi semua kebutuhan yang digambarkan pada fase sebelumnya. Pada tahapan ini juga dilakukan pengujian dari setiap komponen aplikasi yang dihasilkan. Hasil akhir dari fase ini adalah produk jadi aplikasi yang siap untuk digunakan.

- Transition (transisi), proses pekerjaan yang dilakukan pada fase ini adalah penyerahan aplikasi pada pengguna. Proses tersebut meliputi pembuatan manual penggunaan aplikasi, pemeliharaan aplikasi dan pengujian final dari pengguna.

\section{HASIL DAN PEMBAHASAN}

Sesuai dengan proses penelitian yaitu proses pengembagan aplikasi menggunakan metode RUP maka dapat dijelaskan hasil yang dilakukan untuk setiap tahapan yang dilakukan sebagai berikut:

\subsection{Pemodelan Proses Bisnis}

Pemodelan bisnis atau informasi dilakukan menggunakan unified modeling language (UML). UML adalah alat bantu yang dilakukan sesuai dengan konsep pemodelan berorientasi objek, konsep ini dibuat sesuai dengan kehidupan nyata sehingga dapat dengan mudah untuk dipahami. UML digunakan untuk membantu dalam proses pengembangan aplikasi, dimana UML memiliki diagram yang mampu untuk menjembatani komunikasi dan eksplorasi perancangan proses bisnis aplikasi serta proses validasi proses tersebut. Secara umum UML memiliki tiga komponen utama yaitu: "(1) Grady Booch, OOD (Object-Oriented Design), (2) Jim Rumbaugh, OMT (Object Modelling Technique), dan (3) Ivar Jacobson OOSE (Object-Oriented Software Engineering)". UML secara garis besar terdapat tiga jenis diagram yaitu structure diagram, behaviour diagram dan interaction diagram, dimana masing-masing jenis diagram tersebut memiliki fungsi masing-masing. Untuk itu di dalam penelitian ini dibuat masingmasing diagram sesuai dengan jenisnya sebagai berikut:

Diagram pertama adalah use case diagram yang merupakan jenis behavior diagram, diagram ini berfungsi untuk melihat bagaimana aktor dan use case dari aplikasi berinteraksi secara fungsional [12]. Use case diagram yang dihasilkan untuk implementasi algorima Bellman Ford dalam pencarian fasilitas kesehatan klinik terdapat dua jenis aktor yaitu admin dan user. Aktor dengan nama user dapat melihat informasi klinik dan melihat rute klinik, sedangkan aktor admin dapat melakukan interkasi melakukan login, input data klinik, input point peta, dan melakukan Genered atau proses Bellman-Ford. Use case diagram yang dihasilkan untuk implementasi algorimat Bellman Ford seperti yang diperlihatkan pada Gambar 2. 


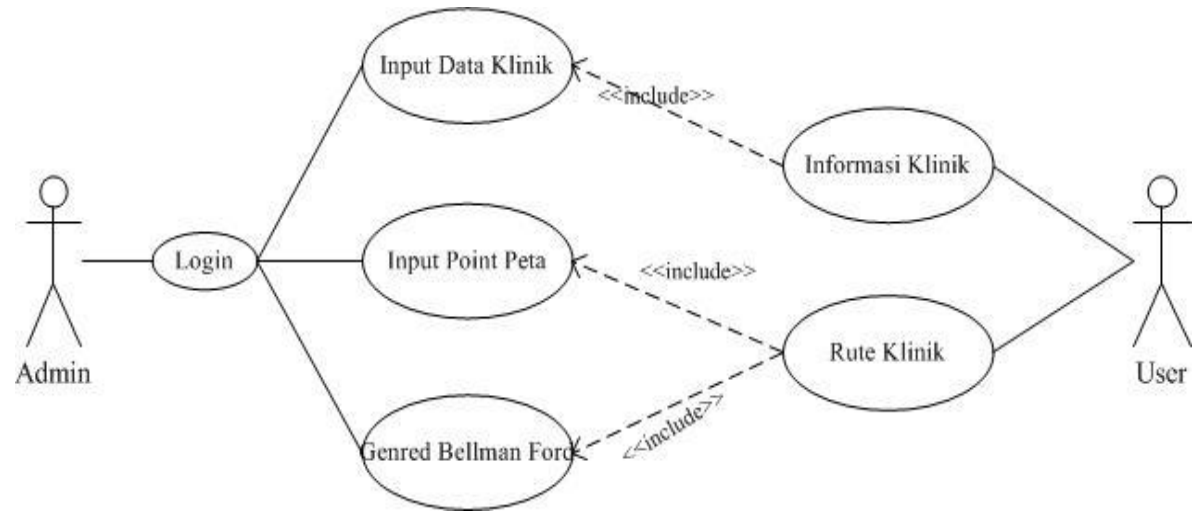

Gambar 2. Use Case Diagram

Selain dari use case diagram jenis diagram yang dibuat juga yaitu structure diagram yang dibuat melalui class diagram. Class diagram merupakan diagram yang digunakan untuk menggambarkan bentuk struktur dari aplikasi yang akan dihasilkan. Class diagram terdiri dari tiga komponen yaitu nama kelas, atribut kelas dan method, dimana nama kelas digunakan sebagai identitas kelas [13]. Untuk itu class diagram dalam aplikasi pencarian klinik dengan mengimplementasikan algorima Bellman Ford dapat dilihat seperti pada Gambar 3. Seperti pada Gambar 3 dapat diketahui bahwa terdapat delapan class pembentuk aplikasi yang terdiri dari klinik, admin, rute, rete alternative, jalu terpendek, vjalur tependek, user dan vrute alternatif. Setiap class memiliki atribut dan method sebagai pembentuk aplikasi.

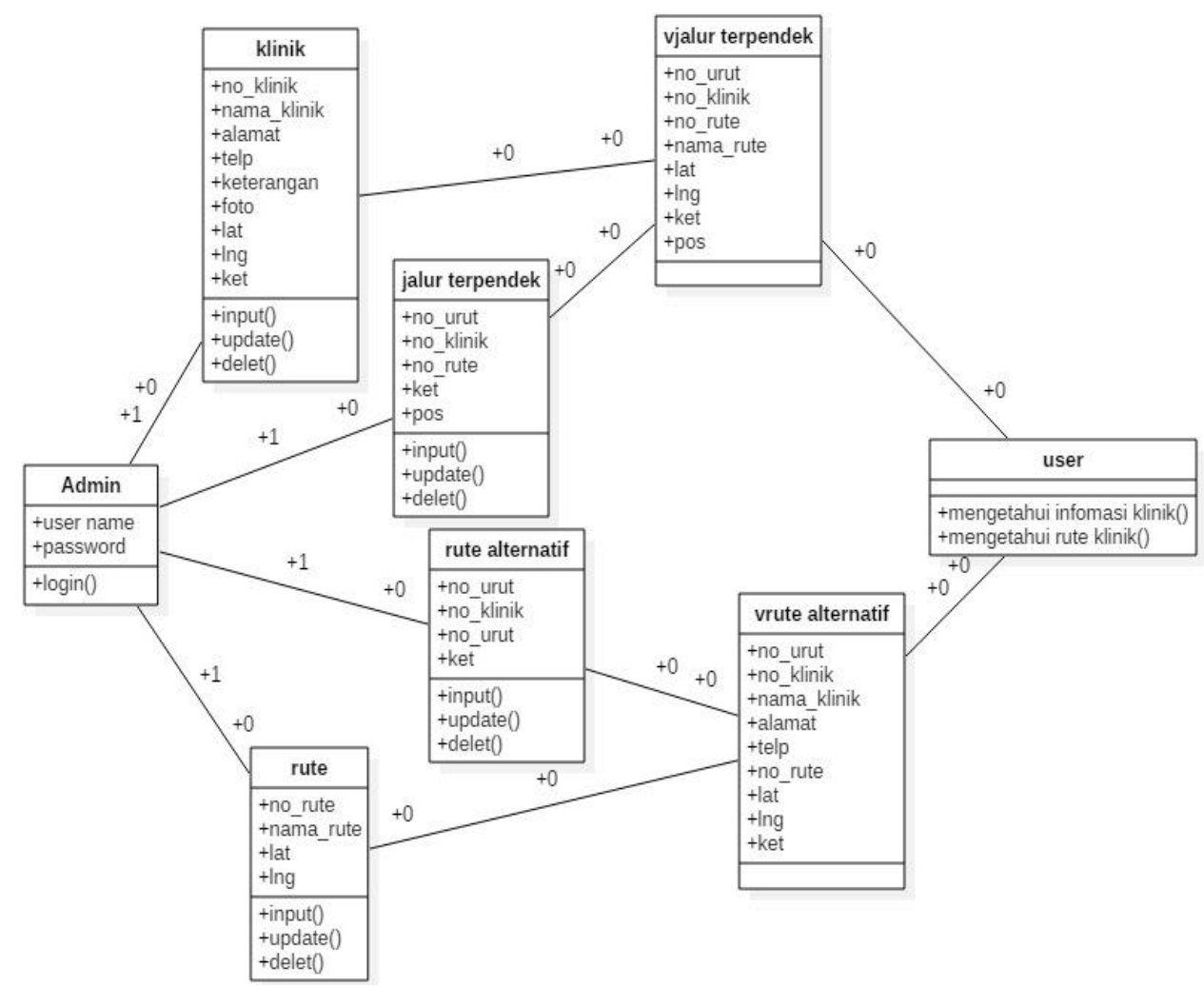

Gambar 3. Class Diagram 
Jenis diagram yang ketika sebagai pemodelan proses bisnis atau informasi aplikasi adalah interaction diagram. interaction diagram merupakan diagram dengan kemampuan untuk menggambarkan hubungan atau interkasi objek di dalam aplikasi dengan aplikasi itu sendiri [14]. Dimana diagram ini digambarkan dalam bentuk activity diagram. Activity diagram sendiri merupakan diagram mampu utuk menggambarkan dan menampilkan prosedur logika apliasi dan proses bisnis dalam sebuah aplikasi sesuaid dengan jenis pengguna yang berinterkasi.

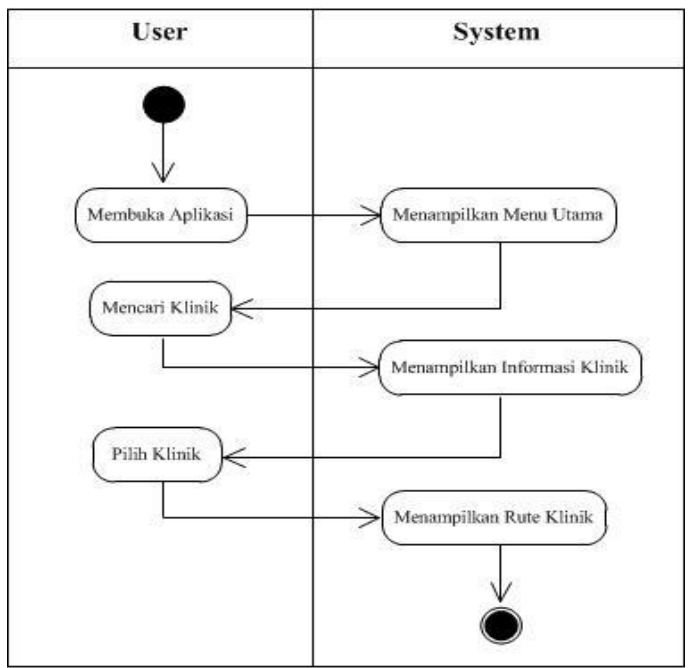

Gambar 4. Activity Diagram User

Activity diagram pada aplikasi pencarian fasilitas kesehatan klinik ini terdapat dua activity diagram, pertama activity diagram untuk jenis pengguna user dan activity diagram admin. Seperti yang diperlihatkan pada Gambar 4 merupakan activity diagram user, dimana activitas yang dilakukan user antara lain dimulai dari membuka aplikasi, mencari klinik dan memilih klinik. Sedangkan dari sisi aplikasi atau sistem melakukan menampilkan menu utama, menampilkan informasi klinik dan menampilkan rute klinik. Selanjutnya adalah activity diagram admin seperti yang diperlihatkan pada Gambar 5. Sesuai Gambar 5 dapat diketahui bahwa activitas yang dilakukan meliputi melakukan login, menampilkan menu utama, melakukan input data klinik, input point peta dan melakukan perhitungan dengan alogrimat Bellman Ford.

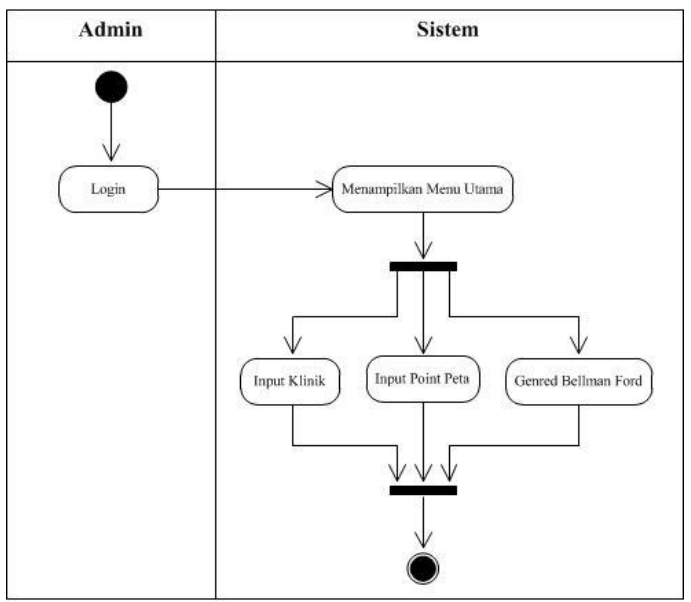

Gambar 5. Activity Diagram Admin

\subsection{Hasi Pengembangan}

Setelah proses pemodelan proses bisnis atau informasi selesai dilakukan maka dilakukan proses pengkodean atau contruction untuk menghasilkan aplikasi pencarian klinik dengan menerapkan algoritma Bellman Ford. Aplikasi yang dihasilkan sesuai dengan pemodelan infromasi tersebut memiliki fitur pengelahan data klinik, data jalan, data rute alternative dan proses perhitungan Bellman Ford. Gambar 6 merupakan dimana pengolahan data klinik dilakukan, data klinik yang dimasukan diantaranya adalah nama klinik, alamat dan telepon klinik.

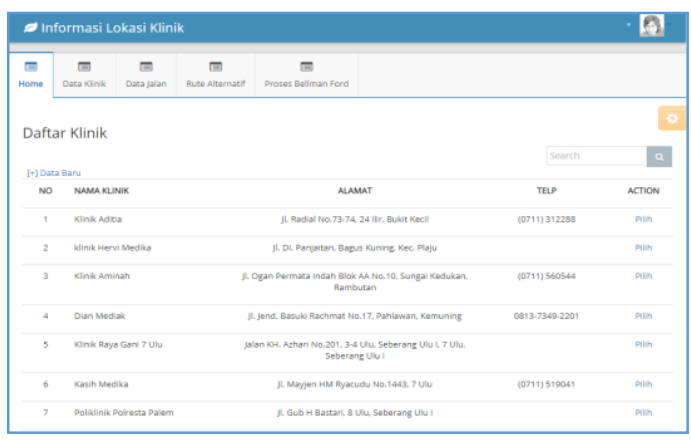

Gambar 6. Daftar Klinik 
Setelah memasukan data klinik maka selanjutnya menentukan posisi atau koordinat klinik dengan cara mengklik data master rute sebagai tujuan ketika dilakukan pencarian. Proses tersebut seperti yang diperlihatkan pada Gambar 7.

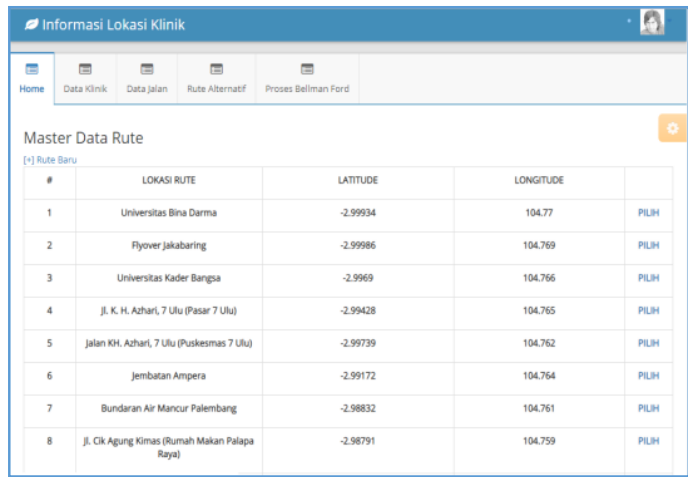

Gambar 7. Master Data Rute

Ketika posisi klinik telah ditentukan seperri yang dilakukan pada Gambar 7 maka selanjutnya adalah menentukan rute alternative untuk menuju klinik tersebut. Proses penentuan tersebut dilakukan memasukan data setiap jalan atau persimpangan jalan dengan memberikan bobot untuk setiap jalan atau persimpangan untuk dilakukan perhitungan dengan bellman Ford seperti yang diperlihatkan paga Gambar 8.

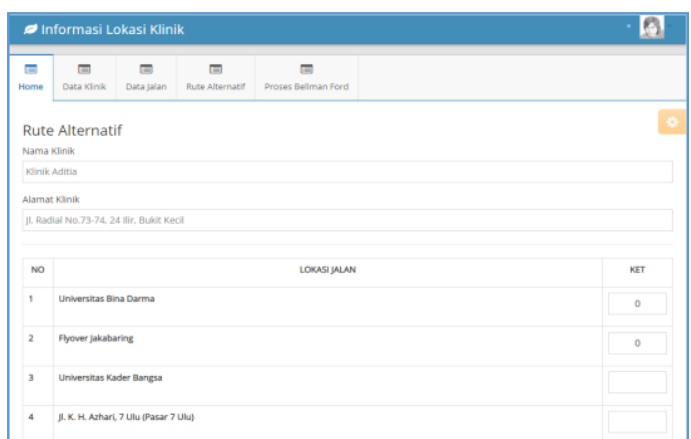

Gambar 8. Penentuan Rute Alternatif

Setelah selesai menentukan bobot untuk masing-masing jalur yang akan dilewati seperti yang dilakukan pada Gambar 8 maka otomatis perhitungan algorima Bellman Ford dilakukan. Kondisi tersebut seperti yang diperlihatkan pada Gambar 9.

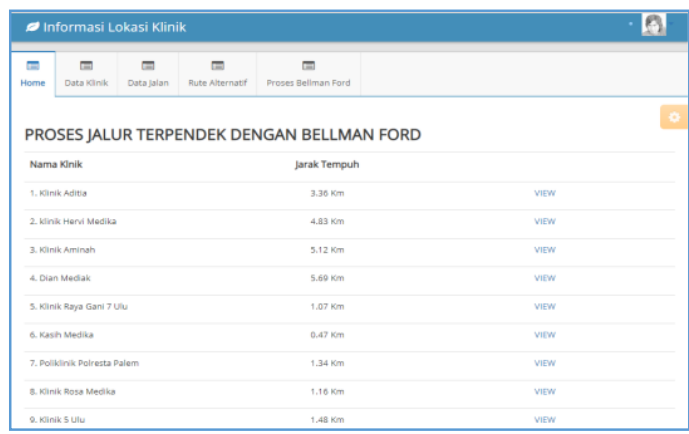

Gambar 9. Penentuna jalur Bellman Ford

Untuk melihat jalur yang direkomendasikan sesuai dengan algoritma Bellman Form maka dapat dilakukan dengan cara mengklik view maka otomatis rute paling pendek untuk dilalui akan ditampilkan seperti yang diperlihatkan pada Gambar 10.

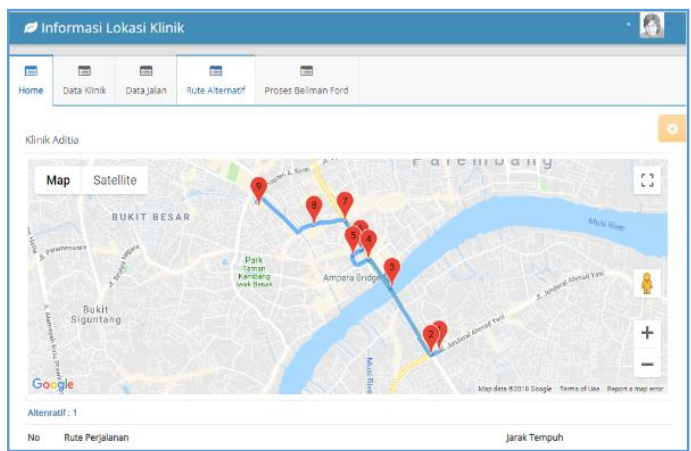

Gambar 10. Activity Diagram Admin

Dari hasil yang diberikan atau yang ditampilkan aplikasi maka dapat disimulasikan proses penentuan jalur terpendek atau rekomendasi jalur yang ditempuh dapat perlihatkan. Seperti yang diperlihatkan Gambar 11 merupakan kondisi awal dari jalur atau rute yang ada pada aplikasi atau data yang dimasukan pada aplikasi. 


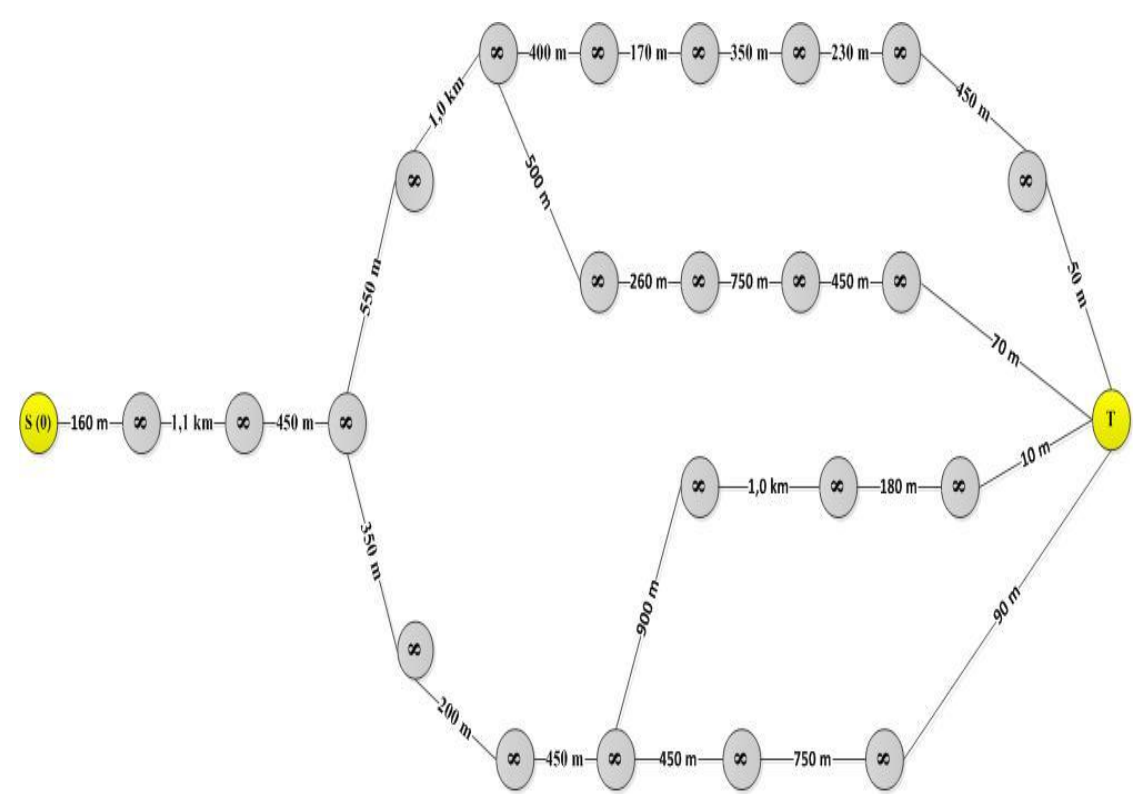

Gambar 11. Kondisi awal rute graph

Sesuai Gambar 11 maka rute perjalanan yang ditempuh dari titik 1 (awal) ke titik 24 (akhir) dapat disumulasikan tujuh scenario perjalanan seabgai berikut:

a. Itermasi Ke 1

Dari itermasi ke 1 maka didapat hasil perhitungan sebagai berikut:

$\mathrm{S}-2=0+160=160$

$2-3=160+1100=1260$

$3-4=1260+450=1710$

Sesuai dengan iterasi ke 1 seperti yang diperlihatkan bahwa no 1 yaitu iterasi dari titik 1 ke titik 2, 3 dan 4. Pada iterasi pertama titik 2 diisi dengan jarak dari titi 1 ke titik 2, titik 3 diisi dengan jarak dari titik 3 dan titik 4 diisi dengan jarak dari titik 3 yang diperoleh jarak minimum dari titik 1 ke titik 2 yaitu $0+160=160 \mathrm{~m}$, titik 2 ke titik 3 yaitu $160+1100=1260 \mathrm{~m}$ dan titik $3 \mathrm{ke}$ titik 4 yaitu $1260+450=1710 \mathrm{~m}$.

b. Iterasi Ke 2

Dari itermasi ke 2 maka didapat hasil perhitungan sebagai berikut:

$4-5=1710+550=2260$

$4-12=1710+350=2060$
$5-6=2260+1000=3260$

$12-13=2060+200=2260$

Sesuai dengan iterasi ke 2 seperti yang diperlihatkan iterasi dari titik 4 ke 5 sejauh $2260 \mathrm{~m}$, titik 4 ke 12 sejauh $2060 \mathrm{~m}$, sedangkan titik 5 ke 6 sejauh 3260 m, titik 12 ke 13 sejauh $2260 \mathrm{~m}$ dan jarak dari titik 13 ke 14 adalah $2710 \mathrm{~m}$.

c. Iterasi Ke 3

Dari itermasi ke 3 maka didapat hasil perhitungan sebagai berikut:

$$
\begin{aligned}
& 6-7=3260+400=3660 \\
& 6-20=3260+500=3760 \\
& 14-19=2710+900=3610 \\
& 14-15=270+450=3160
\end{aligned}
$$

Sesuai dengan iterasi ke 3 seperti yang diperlihatkan iterasi dari titik 6 ke titik 7 , titik 6 ke titik 20 sedangkan titik 14-17 dan titik 14-15 dengan total jarak masing masing adalah $3660 \mathrm{~m}, 3760 \mathrm{~m}, 3610 \mathrm{~m}$, $3160 \mathrm{~m}$. 
d. Iterasi Ke 4

Dari itermasi ke 4 maka didapat hasil perhitungan sebagai berikut:

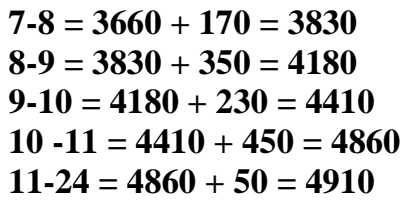

Sesuai dengan iterasi ke 4 seperti yang diperlihatkan iterasi dari titik 7 ke 8 , titik 8 ke 9, titik 9 ke 10, titik 10 ke 11 dan titik 11 ke 24 dengan total jarak masing - masing adalah $3830 \mathrm{~m}, 4180 \mathrm{~m}, 4410 \mathrm{~m}, 4860 \mathrm{~m}$, $4910 \mathrm{~m}$.

e. Iterasi Ke 5

Dari itermasi ke 5 maka didapat hasil perhitungan sebagai berikut:

$$
\begin{aligned}
& 20-21=3760+260=4020 \\
& 21-22=4020+750=4770 \\
& 22-23=4770+450=5220 \\
& 23-24=5220+70=5290
\end{aligned}
$$

Sesuai dengan iterasi ke 5 seperti yang diperlihatkan dari titik 20 ke titik 21, titik 21 ke titik 22 yaitu sejauh $4020 \mathrm{~m}, 4770 \mathrm{~m}$ sedangkan titik 22-23 dan titik 23-24 dengan jarak masing-masing adalah $5220 \mathrm{~m}, 5290$ $\mathrm{m}$.

\section{f. Iterasi Ke 6}

Dari itermasi ke 6 maka didapat hasil perhitungan sebagai berikut:

$$
\begin{aligned}
& 17-18=3610+1000=4610 \\
& 18-19=4610+180=4790 \\
& 19-24=4790+10=4800
\end{aligned}
$$

Sesuai dengan iterasi ke 6 seperti yang diperlihatkan iterasi keenam menghasilkan nilai masing - masing adalah jarak nilai dari 17-18 sejauh $4610 \mathrm{~m}$, dari titik 18-19 sejauh $4790 \mathrm{~m}$ dan 19-24 sejauh $4800 \mathrm{~m}$.

\section{g. $\quad$ Iterasi $\mathrm{Ke} 7$}

Dari itermasi ke 7 maka didapat hasil perhitungan sebagai berikut:

$15-16=3160+750=3910$
$16-24=3910+90=4000$

Sesuai dengan iterasi ke 7 seperti yang diperlihatkan iterasi ketujuh dari titik $15 \mathrm{ke}$ 16 dan titik 16 ke 24 dengan total jarak masing - masing adalah $3910 \mathrm{~m}$ dan $4000 \mathrm{~m}$. Dari iterasi yang dilakukan maka rekomendasi atau jalur terpendek sesuai dengan ketentuan algoritma Bellman Ford sebagai berikut:

1. Rekomendasi rute pertama yaitu1-23-4-12-13-14-15-16-24 dengan jarak $4000 \mathrm{~m} /(4 \mathrm{~km})$.

2. Rute kedua yaitu 1-2-3-4-12-13-1417-18-19-20-24 dengan jarak $4800 \mathrm{~m}$ / $(4,8 \mathrm{~km})$.

3. Rekomendasi rute ketiga yaitu 1-2-34-5-6-7-8-9-10-11-24 dengan jarak $4910 \mathrm{~m} /(4,9 \mathrm{~km})$

4. Rekomendasi rute keempat yaitu 1-23-4-5-6-20-21-22-23-24 dengan jarak $5290 \mathrm{~m} /(5,2 \mathrm{~km})$.

\section{KESIMPULAN}

Sesuai dengan proses penelitian yang dilakukan dalam pengembangan aplikasi pencarian fasilitas kesehatan klinik dengan menerapkan algorima Bellman Ford maka dapat disimpulkan beberapa hal sebagai berikut:

1. Aplikasi yang dihasilkan telah dikembangkan dengan prosedur ilmiah yaitu menggunakan metode pengembangan Rational Unified Process dengan tahapan pengembangan yaitu inception, elaboration, construction dan transition.

2. Aplikasi yang dihasilkan memiliki fitur pengolahan data klinik, lokasi klinik, penentuan alternative rute dan proses algoritma Bellman Ford sehingga dapat dijadikan alat bantu dalam pencarian rute alternatif atau rekomendasi rute.

3. Algorima Bellman Ford dapat memberikan alternatif atau rekomendasi rute perjalanan yang 
dibuktikan dari perhitungan atau simulasi yang dilakukan dalam melakukan pencarian rute.

\section{SARAN}

Saran yang yang peneliti berikan yaitu hendaknya melakukan perbandingan dengan algoritma lain atau dengan kasus lain untuk melihat akurasi atau efektifitas dari algoritma Bellman Ford secara lebih mendalam agar menghasilkan hasil penelitian yang memiliki dampak yang lebih baik.

\section{DAFTAR PUSTAKA}

[1] S. Gifary, "Intensitas Penggunaan Smartphone Dan Perilaku Komunikasi (Studi Pada Pengguna Smartphone di Kalangan Mahasiswa Program Studi Ilmu Komunikasi Universitas Telkom)," $J$. Sosioteknologi, vol. 14, no. 2, 2015.

[2] D. R. Rahadi and Z. Zanial, "Perilaku pengguna smartphone di Palembang," in Annual Research Seminar (ARS), 2015, vol. 1, no. 1, pp. 161-166.

[3] APJII, "Indonesia Internet Service Provider Association: Penetrasi dan Perilaku Pengguna Internet Indonesia," Jakarta, 2018.

[4] C. Ramadani, "Dasar Algoritma dan struktur data dengan Bahasa Java," Yogyakarta Penerbit Andi, 2015.

[5] N. Fadhlia, "Rekomendasi Rute Spbu Terdekat Menggunakan Algoritma Bellman-Ford Berbasis Android."

[6] D. Syapnika and E. R. Siagian, "Penerapan Algoritma Minimax pada Permainan Checkers," JURIKOM (Jurnal Ris. Komputer), vol. 2, no. 6, 2015.

[7] S. Hamdi and P. Prihandoko, "Analisis Algoritma Dijktra dan Algoritma Bellman-Ford Sebagai
Penentuan Jalur Terpendek Menuju Lokasi Kebakaran (Studi Kasus: Kecamatan Praya Kota)," Energy, vol. 8, no. 1, pp. 26-32, 2018.

[8] E. T. H. Hutasoit, "Pencarian Rute Terpendek Menggunakan Algoritma Bellman-Ford (Studi Kasus: PT. JNE Medan)," J. Sist. Komput. dan Inform., vol. 1, no. 1, pp. 20-25, 2019.

[9] M. Rofiq and R. F. Uzzy, "Penentuan Jalur Terpendek Menuju Cafe Di Kota Malang Menggunakan Metode Bellman-Ford dengan Location Based Service Berbasis Android," J. Ilm. Teknol. Inf. Asia, vol. 8, no. 2, pp. 49-64, 2014.

[10] B. Tujni and H. Hutrianto, "PENGEMBANGAN

PERANGKAT

LUNAK

MONITORING

WELLIES

DENGAN

METODE

WATERFALL MODEL," J. Ilm.

Matrik, vol. 22, no. 1, pp. 122-130, 2020.

[11] R. As and M. Shalahuddin, "Rekayasa perangkat lunak terstruktur dan berorientasi objek," Inform. Bandung, 2013.

[12] F. Purwaningtias and C. Mukmin, "PEMODELAN ENTERPRISE RESOURCE PLANNING MENGGUNAKAN ODOO PADA Z-TECH KOMPUTER," KLIKKUMPULAN J. ILMU Komput., vol. 6, no. 3, pp. 275-283, 2019.

[13] A. Syazili and W. Chandra, "Pemodelan UML untuk Perangkat Lunak Antrian pada Klinik Kesehatan," in Seminar Nasional Teknologi Informasi dan Komunikasi (SEMNASTIK), 2018, vol. 1, no. 1, pp. 10-15. 
[14] A. Hayat, T. Prastica, S. Susanti, and

A. Isyamarwati, "Prototipe Sistem Informasi Persediaan Barang Logistik Berbasis Web Dengan Pemodelan UML," Proc. Konf. Nas. Sist. dan Inform., 2015. 